\title{
Early Stages of Platinum Electrodeposition on Highly Oriented Pyrolitic Graphite: Scanning Tunneling Microscopy Imaging and Reaction Pathway
}

\author{
J. L. Zubimendi, ${ }^{\dagger}$ L. Vázquez, ${ }^{\ddagger}$ P. Ocón, ${ }^{\S}$ J. M. Vara, ${ }^{\S}$ W. E. Triaca, ${ }^{\dagger}$ R. C. Salvarezza, ${ }^{\dagger}$ and \\ A. J. Arvia", \\ Instituto de Investigaciones Fisicoquimicas Teóricas y Aplicadas (INIFTA), Casilla de Correo 16, Sucursal 4, \\ (1900) La Plata, Argentina; Departamento de Fisica Aplicada C-XII, Consejo Superior de Investigaciones \\ Cientificas, Instituto de Ciencia de Materiales, sede B, Universidad Autónoma de Madrid, 28049 Madrid, \\ Spain, and Departamento de Quimica-Fisica Aplicada, C-II, Universidad Autónoma de Madrid, \\ 28049 Madrid, Spain
}

Received: October 14, 1992; In Final Form: February 8, 1993

\begin{abstract}
The early stages of Pt electrodeposition (0.675-0.620 V vs RHE) on highly oriented pyrolytic graphite (HOPG) from chloroplatinic acid at $25^{\circ} \mathrm{C}$ have been studied by ex-situ STM and SEM imaging complemented with electrochemical data. Nucleation and 3D growth of Pt initiate at HOPG surface defects. Large Pt agglomerates containing flat crystallites with well-defined geometries are found around HOPG steps. Pt crystallites formed by 1-2 nm size clusters become more compact as the electrodeposition potential is shifted negatively or the $\mathrm{Pt}$ electrodeposited charge is increased. High-resolution STM imaging reveals large uncovered HOPG areas with the nearest-neighbor $\mathrm{C}-\mathrm{C}$ distance $d=0.24 \pm 0.02 \mathrm{~nm}$ and flat hexagonal $\mathrm{Pt}$ crystallites. Electrochemical data combined with STM imaging can be interpreted in terms of a diffusion-controlled $\mathrm{Pt}(\mathrm{IV})$ to $\mathrm{Pt}$ (II) reaction at HOPG and a surface reaction leading to $\mathrm{Pt}(0)$ at HOPG defects.
\end{abstract}

\section{Introduction}

The knowledge of the early stages of metal electrodeposition on well-defined electrochemical interfaces becomes of outmost importance to prove the validity of models for new phase growth and the participation of surface chemical transformations and phase transitions in this type of process.'

In recent years, scanning tunneling microscopy (STM) has become a promising technique to obtain structural information about electrochemical interfaces at the atomic level. Thus, very interesting results for the electrodeposition of metals ${ }^{2-8}$ have been found, ${ }^{3-6}$ allowing the characterization of well-ordered metal overlayers and the imaging of deposits growth from the submonolayer level to thicknesses equivalent to several atomic layers. ${ }^{9}$

STM imaging of metal deposits grown on solid substrates either from vapor ar by electrochemical methods indicates that metal nuclei are formed at substrate surface defects such as step edges and dislocations. ${ }^{7}$ Subsequently, the initial small $3 \mathrm{D}$ nuclei evolve to form well-defined crystallites. ${ }^{9}$ A number of metal surface properties such as the activity and the selectivity for catalytic reactions are determined by the structure, size, and morphology of crystallites. ${ }^{10}$

The present increasing interest to characterize $P t$ deposits grown on carbon substrates from vapor, chemical impregnation, or electrodeposition by using STM ${ }^{1-13}$ comes from the fact that different types of $\mathrm{Pt}$ deposits are used as catalysts in several heterogeneous processes as well as in electrocatalysis. The effect of the supported crystallites structure on these processes has been thoroughly studied.14-16

The overpotential (opd) $\mathrm{Pt}$ electrodeposition from $\mathrm{H}_{2} \mathrm{PtCl}_{6}$ on carbon substrates produces a large variety of microtopographies with specific electrocatalytic properties. ${ }^{17}$ The overall process has been interpreted through two successive steps, namely, the $\mathrm{Pt}(\mathrm{IV})$ to $\mathrm{Pt}$ (II) and the $\mathrm{Pt}$ (II) to $\mathrm{Pt}(0)$ electrochemical reactions and the possible formation of $\mathrm{Pt}(0)$ from a $\mathrm{Pt}(\mathrm{II})$ disproportionation reaction. ${ }^{18-20}$

This work examines the early stages of Pt electrodeposition on highly oriented pyrolytic graphite (HOPG) from $\mathrm{H}_{2} \mathrm{PtCl}_{6}$ solutions

\footnotetext{
+ Instituto de Investigaciones Fisicoquímicas Teóricas y Aplicadas.

I Instituto de Ciencia de Materiales.

\&niversidad Autónoma de Madrid.
}

combining electrochemical data and ex-situ STM imaging at both nanometer and atomic level resolution. These results allow us to discuss several kinetic aspects of Pt electrodeposition on carbon substrates. ${ }^{18-20}$

\section{Experimental Results}

The Pt electrodeposition on HOPG from $\mathrm{H}_{2} \mathrm{PtCl}_{6}$ solution was studied using SEM and ex-situ STM combined with conventional electrochemical techniques. These techniques were employed to determine the potential ranges most appropriate for STM images of the early stages of Pt electrodeposition and to follow the kinetics of the electrochemical reaction.

The $\mathrm{H}_{2} \mathrm{PtCl}_{6}$ electroreduction was preferentially investigated in aqueous $3.86 \times 10^{-2} \mathrm{M} \mathrm{H}_{2} \mathrm{PtCl}_{6}+1.1 \mathrm{M} \mathrm{HCl}^{17}$ on freshly exfoliated HOPG working electrodes at $25^{\circ} \mathrm{C}$. Occasionally, some experiments using spectroscopic carbon working electrodes (0.017- $\mathrm{cm}^{2}$ geometric area), $x \mathrm{M} \mathrm{H}_{2} \mathrm{PtCl}_{6}+1 \mathrm{M} \mathrm{ClH}(3.86 \times$ $10^{-3} \mathrm{M}<x<3.86 \times 10^{-2} \mathrm{M}$ ), and $3.8 \times 10^{-3} \mathrm{M} \mathrm{H}_{2} \mathrm{PtCl}_{6}+x^{\prime}$ $\mathrm{M} \mathrm{K}_{2} \mathrm{PtCl}_{4}\left(0<x^{\prime}<6.5 \times 10^{-3} \mathrm{M}\right)+1.1 \mathrm{M} \mathrm{HCl}$ were performed to clarify some specific kinetic aspects of the $\mathrm{H}_{2} \mathrm{PtCl}_{6}$ electroreduction reaction. Electrochemical runs were made with a conventional electrochemical cell using a large area polycrystalline Pt counter electrode and a reversible hydrogen electrode (RHE) in aqueous $1.1 \mathrm{M} \mathrm{HCl}$ as reference. Potentials in the text are given on the RHE scale.

Solutions were prepared from a.r. quality chemicals and Milli-Q water. Prior to each electrochemical run the working solution was deaerated by bubbling purified $\mathbf{N}_{2}$.

The apparent current density $(j)$ vs potential $(E)$ profiles at different sweep rates $(v)$ were recorded from the rest potential $\left(E_{\mathrm{s}} \cong 0.75 \mathrm{~V}\right)$ to $0.0 \mathrm{~V}$. The electroreduction current transients at a constant potential $\left(E_{\mathrm{d}}\right)$ were also found. The potential was stepped from $E_{\mathrm{s}}$ to $E_{\mathrm{d}}\left(0.75 \mathrm{~V}<E_{\mathrm{d}}<0.60 \mathrm{~V}\right)$. The apparent charge density was referred to as the substrate geometric area. Most runs were made with quiescent solution, and the influence of solution stirring was qualitatively proved. Blanks were systematically performed.

For SEM and STM imaging, Pt electrodeposits on HOPG were prepared at $E_{\mathrm{d}}$ recording simultaneously the $j$ vs $t$ curves. All $E_{\mathrm{d}}$ values were negatively shifted with respect to the 
equilibrium potentials of the $\mathrm{Pt}(\mathrm{IV}) / \mathrm{Pt}$ (II) and $\mathrm{Pt}(\mathrm{II}) / \mathrm{Pt}(0)$ redox couples, $E^{\circ}{ }_{1}=0.726 \mathrm{~V}$ and $E^{\circ}{ }_{2}=0.758 \mathrm{~V}$ at $298 \mathrm{~K}$, respectively. ${ }^{21}$ The apparent $P t$ electroreduction charge density $\left(q_{\mathrm{c}}\right)$ referred to as the geometric area of the HOPG electrode was changed in the 1-3 $\mathrm{mC} \mathrm{cm}^{-2}$ range by controlling the Pt electrodeposition time and the applied potential. The electrodeposition time was comprised between 60 and $180 \mathrm{~s}$.

The topography of the working electrodes after $\mathrm{Pt}$ electrodeposition was studied at the micrometer range by SEM and nanometer and atomic resolution ranges by ex-situ STM. The working electrode was removed from the cell, gently rinsed with $\mathrm{O}_{2}$-free Milli-Q water, and finally dried under $\mathrm{N}_{2}$ at room temperature.

STM images were obtained within the first $6 \mathrm{~h}$ of sample withdrawal from the cell solution by means of a homemade piezotube STM operating in air. An Atomis 4 control unit and software were used. The tips were poorly cut from $0.5-\mathrm{mm}$ diameter $\mathrm{Pt}$ wires. Topographic mode imaging was run using bias voltages in the $0.03-0.1 \mathrm{~V}$ range at $1-3 \mathrm{nA}$ constant current. The current mode was used for atomic resolution imaging as it allows the use of high scan rates. In this case, the whole collection time was about $10 \mathrm{~s}$.

As the precision of the atomic scale distances measured through STM is mainly influenced by the hysteresis and the thermal drift of the piezoelectric tube, different experimental ways were used to minimize these effects. Thus, the atomic distances were measured from the STM images along the $x$ axis where the atomic corrugation is imaged faster (ca. $0.05 \mathrm{~s} \mathrm{scan}{ }^{-1}$ ), and the corresponding error bar was estimated as $\pm 10 \%$. The same error applies to the angle measurements from the STM images.

The HOPG surface imaging was used for STM calibration. These images (typically $900 \times 900 \mathrm{~nm}^{2}$ ) show flat surface areas with some steps. The typical hexagonal array of $\mathrm{C}$ atoms with the interatomic distance $d=0.24 \pm 0.02 \mathrm{~nm}$ can be observed at the highest resolution $\left(40 \times 40 \mathrm{~nm}^{2}\right)$. In this case, one of every two $\mathrm{C}$ atoms was imaged. ${ }^{12}$ These data were used to confirm the $10 \%$ error bar in the distance measurements.

Data were acquired in a fully automated workstation and stored as digitized images with $200 \times 200$ or $400 \times 400$ pixels. The atomic distances given in this work have been obtained from raw data images, although they are shown after plane removal and smoothening by the standard image processing provided by Atomis.

There is no universally accepted criteria yet concerning the most satisfactory STM operating mode in electrochemistry. Thus, the in-situ STM technique may alter the local potential and diffusion fields at the working electrode surface which may be induced by the tip. ${ }^{7}$ On the other hand, ex-situ STM may result in surface reconstruction induced by either oxygen or other impurities adsorbed from the atmosphere during imaging. ${ }^{22}$ Recent results on $\mathrm{Ag}$ electrodeposition on graphite ${ }^{9}$ and $\mathrm{S}$ deposition on $\mathrm{Pt}(100)$ surfaces $^{23}$ have shown that under certain experimental conditions ex-situ imaging with atomic resolution is possible without contaminants interference. In this case, the low reactivity of HOPG and $P t$ in contact with the atmosphere at room temperature justifies the use of the ex-situ STM technique. However, in this work, the possible interference of contaminants (O, C, S, or hydrocarbons) adsorbed on $\mathrm{Pt}$ from the air during STM imaging was tested through the $\mathrm{O}$ adatom and the $\mathrm{H}$ adatom electrosorption voltammetry. Depending on the potential range applied, an $\mathrm{O}$ adatom and a $\mathrm{H}$ adatom monolayer can be formed on $\mathrm{Pt}$ in aqueous acid electrolytes, and these reactions are extremely sensitive to surface contaminants. ${ }^{24}$ Accordingly, voltammograms on a $\mathrm{Pt}$ single-crystal microsphere in $0.5 \mathrm{M} \mathrm{H}_{2^{-}}$ $\mathrm{SO}_{4}$ were run at $0.1 \mathrm{~V} \mathrm{~s}^{-1}$ to determine both the $\mathrm{O}$ adatom and the $\mathrm{H}$ adatom monolayer charge. Afterward, the $\mathrm{Pt}$ single crystal was exposed to the atmosphere for $6 \mathrm{~h}$ and then returned to the cell to remeasure voltammetric charges related to the $O$ adatom

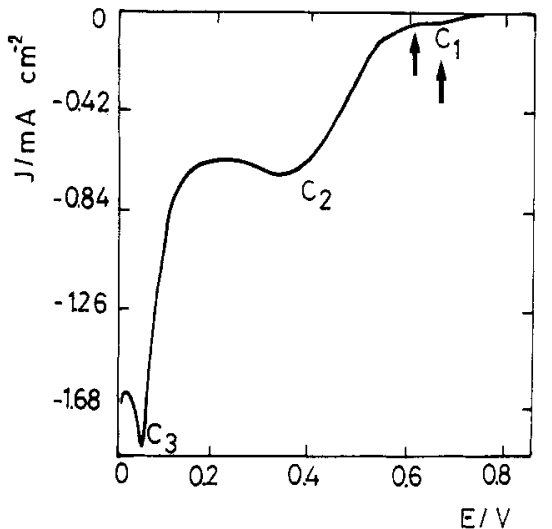

Figure 1. Linear potential sweep voltammogram run at $5 \times 10^{-3} \mathrm{~V} \mathrm{~s}^{-1}$ from 0.75 to $0 \mathrm{~V}$ for $\mathrm{HOPG}$ in aqueous $3.86 \times 10^{-2} \mathrm{M} \mathrm{H}_{2} \mathrm{PtCl}_{6}+1.1 \mathrm{M}$ $\mathrm{HCl}$ at $25^{\circ} \mathrm{C}$. The arrows indicate the potentials at which the Pt deposits for STM and SEM imaging were grown.

and the $\mathrm{H}$ adatom electrosorption processes. The absence of an $O$ adatom electrodesorption voltammetric peak during the linear potential sweep initiated from $0.85 \mathrm{~V}$ downward allows us to conclude that practically no $\mathrm{O}$ adatoms have been formed on $\mathrm{Pt}$ after 6-h exposure to air. Apart from that, the decrease in the $\mathrm{H}$ adatom electrosorption charge indicates that the $\mathrm{Pt}$ surface coverage by contaminants is less than 0.2 of a monolayer when the specimens were immersed in the electrolyte solution. But these results have little bearing on the amount of $C$ present on $\mathrm{Pt}$ in air, as STM observations of cleaned $\mathrm{Pt}(111)$ surfaces reveal $\mathrm{C}$ islands which are usually located at kinks along monatomic steps of the $\mathrm{Pt}(111)$ surface. ${ }^{25,26}$ Therefore, the possibility that a carbidic overlayer is formed on Pt electrodeposits up to 6-h exposure to air makes uncertain atomic resolution data obtained at $\mathrm{Pt}$ crystallite surfaces.

\section{Results}

3.1. Electrochemical Data. The cathodic current density $(j)$ vs potential $(E)$ profile of a $H O P G$ electrode recorded at 0.005 $\mathrm{V} \mathrm{s}^{-1}$ from 0.75 to $0 \mathrm{~V}$ in aqueous $3.86 \times 10^{-2} \mathrm{M} \mathrm{H}_{2} \mathrm{PtCl}_{6}+1.1$ $\mathrm{M} \mathrm{HCl}$ (Figure 1) shows a small current plateau $\left(\mathrm{C}_{1}\right)$ at $0.64 \mathrm{~V}$ followed by a broad cathodic current peak $\left(\mathrm{C}_{2}\right)$ at $0.33 \mathrm{~V}$ and a sharp peak $\left(\mathrm{C}_{3}\right)$ at ca. $0.05 \mathrm{~V}$. This voltammogram shape is qualitatively comparable to the shape of those obtained on glassy carbon ${ }^{18}$ and PAN-based carbon fibers ${ }^{19}$ in the same solution; peaks $C_{1}$ and $C_{2}$ heights increase linearly with the square root of $v$, whereas solution stirring produced by $\mathrm{N}_{2}$ bubbling increases both current contributions at a constant $v$.

The current plateau $\left(\mathrm{C}_{1}\right)$ has been related to the electroreduction of $\mathrm{Pt}$ (IV) to $\mathrm{Pt}$ (II) species. ${ }^{19} \mathrm{Peak} \mathrm{C}_{2}$ has been attributed to the electroreduction of $\mathrm{Pt}(\mathrm{IV})$ and $\mathrm{Pt}(\mathrm{II})$ to $\mathrm{Pt}(0)$, and peak $\mathrm{C}_{3}$ has been associated with the simultaneous electrodeposition of $\mathrm{Pt}$ and the discharge of $\mathrm{H}^{+}$ions. A disproportionation reaction of $\mathrm{Pt}(\mathrm{II})$ species into $\mathrm{Pt}(0)$ and $\mathrm{Pt}(\mathrm{IV})$ species has also been included as a process taking place in the potential range of peak $\mathrm{C}_{1},{ }^{18}$ although the participation of this reaction is opened to discussion after the results for PAN-based carbon fiber electrodes. ${ }^{19}$ Hence, in this work most of the efforts are focused on the investigation of possible Pt electrodeposition on HOPG in the potential range of the current plateau $\mathrm{C}_{1}$.

3.2. Current Transients. The cathodic current transients resulting from HOPG electrodes immersed in aqueous $3.86 \times$ $10^{-2} \mathrm{M} \mathrm{H}_{2} \mathrm{PtCl}_{6}+1.1 \mathrm{M} \mathrm{HCl}$, by stepping from the rest potential to $E_{\mathrm{s}}=0.62 \mathrm{~V}$, a potential value lying within the potential range of plateau $\mathrm{C}_{1}$, show a continuous decreasing current (Figure 2a). The $j$ vs $t^{-1 / 2}$ plot yields a straight line (Figure 2b) as one would expect for a cathodic process under diffusion control. However, in contrast to a simple diffusional process, for $t \rightarrow \infty$, the straight line gives a residual cathodic current $\left(j_{\infty}\right)$. 

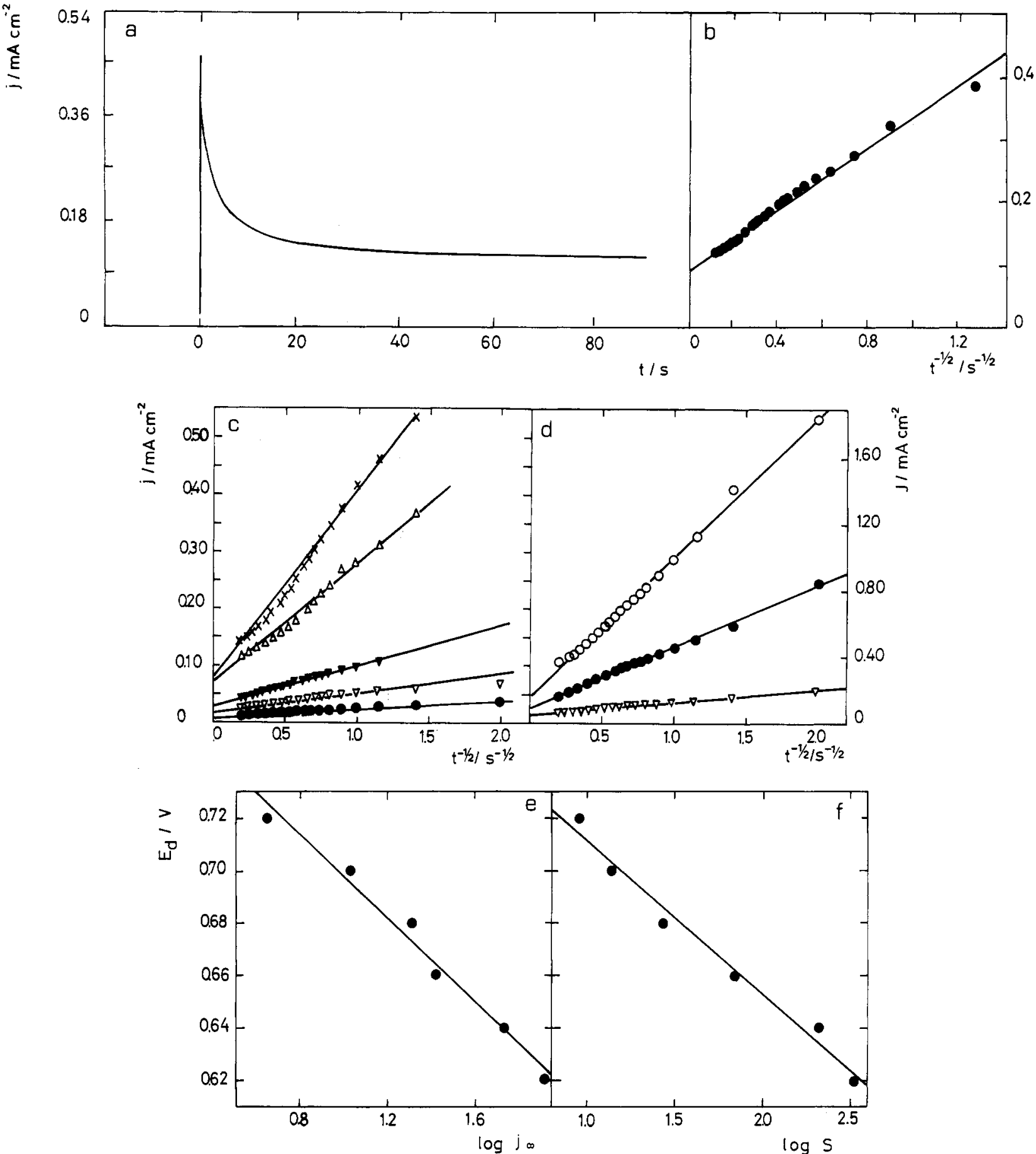

Figure 2. (a) A typical current transient for Pt electrodeposition on $\mathrm{HOPG}$ at $E=0.62 \mathrm{~V}$ from aqueous $3.86 \times 10^{-2} \mathrm{M} \mathrm{H}_{2} \mathrm{PtCl}_{6}+1.1 \mathrm{M} \mathrm{HCl}$. (b) $j$ vs $t^{-1 / 2}$ plot for the current transient shown in (a). (c) $j$ vs $t^{-1 / 2}$ plots resulting on spectroscopic carbon in aqueous $3.86 \times 10^{-2} \mathrm{M} \mathrm{H}_{2} \mathrm{PtCl}_{6}+1.1 \mathrm{M}$ $\mathrm{HCl}$ at different $E_{\mathrm{d}}$ values. $(\times) E_{\mathrm{d}}=0.62 \mathrm{~V},(\Delta) E_{\mathrm{d}}=0.64 \mathrm{~V},(\nabla) E_{\mathrm{d}}=0.66 \mathrm{~V},(\nabla) E_{\mathrm{d}}=0.68 \mathrm{~V},(\bullet) E_{\mathrm{d}}=0.70 \mathrm{~V}$. (d) $j \mathrm{vs} t^{-1 / 2}$ plots resulting on spectroscopic carbon at $E_{\mathrm{d}}=0.62 \mathrm{~V}$ in aqueous $x \mathrm{M} \mathrm{H}_{2} \mathrm{PtCl}_{6}+1.1 \mathrm{M} \mathrm{HCl}$. (O) $x=3.86 \times 10^{-2} \mathrm{M} \mathrm{H}_{2} \mathrm{PtCl}_{6},(\bullet) x=1.93 \times 10^{-2} \mathrm{M} \mathrm{H}_{2} \mathrm{PtCl}_{6}$, ( $\nabla) x=3.86 \times 10^{-3} \mathrm{M} \mathrm{H}_{2} \mathrm{PtCl}_{6}$. (e) $E_{\mathrm{d}}$ vs $\log j_{\infty}$ plot from $j_{\infty}$ data depicted in (c). (f) $E_{\mathrm{d}}$ vs $\log S$ plot from $S$ data depicted in (c).

On the other hand, the cathodic current transients found with spectroscopic carbon at different $\mathrm{H}_{2} \mathrm{PtCl}_{6}$ concentrations in 1.1 $\mathrm{M} \mathrm{HCl}$, in either the presence or the absence of $\mathrm{K}_{2} \mathrm{PtCl}_{4}$ covering the potential range of plateau $C_{1}$, yield the following kinetic information. (i) The slope $(S)$ of the straight line resulting from the $j$ vs $t^{-1 / 2}$ plot increases as $E_{\mathrm{d}}$ is decreased at constant $\mathrm{H}_{2} \mathrm{PtCl}_{6}$ concentration (Figure $2 \mathrm{c}$ ). (ii) The values of both $S$ and $j_{\infty}$ increase according to the $\mathrm{H}_{2} \mathrm{PtCl}_{6}$ concentration at constant $E_{\mathrm{d}}$ (Figure 2d). (iii) In the absence of $\mathrm{K}_{2} \mathrm{PtCl}_{4}$ the value of $j_{\infty}$ increases with $E_{\mathrm{d}}$ fitting a $\log j_{\infty}$ vs $E_{\mathrm{d}}$ linear relationship with a slope near to $0.06 \mathrm{~V} /$ decade (Figure 2e). (iv) The value of $S$ changes with $E_{\mathrm{d}}$ according to a $E_{\mathrm{d}}$ vs $\log S$ linear relationship with a slope equal to $0.06 \mathrm{~V} /$ decade (Figure $2 \mathrm{f}$ ). This slope is independent of $\mathrm{K}_{2^{-}}$-
$\mathrm{PtCl}_{4}$ concentration. (v) In the presence of $\mathrm{K}_{2} \mathrm{PtCl}_{4}$ the value of $j_{\infty}$ decreases as the $\mathrm{K}_{2} \mathrm{PtCl}_{4}$ concentration is increased. The decrease of $j_{\infty}$ fits a $j_{\infty} \propto c_{\mathrm{Pt}(\mathrm{II})} \exp \left(-\eta_{\mathrm{c}}\right)$ dependence, where $c_{\mathrm{Pt}(\mathrm{II})}$ stands for the $\mathrm{K}_{2} \mathrm{PtCl}_{4}$ concentration in the solution and $\eta_{\mathrm{c}}$ refers to the cathodic overvoltage defined as $\eta_{\mathrm{c}}=E_{\mathrm{d}}-E_{\mathrm{s}}$. The value of $E_{\mathrm{s}}$, the rest potential of the system, is very close to the equilibrium potential of the $\mathrm{Pt}(\mathrm{II}) / \mathrm{Pt}(\mathrm{IV})$ redox system. ${ }^{21}$

After running the cathodic current transients in the potential range of plateau $C_{1}$, the characteristics of the working electrode surface were tested throughout the following experiments. The working electrode was removed from the $x \mathrm{M} \mathrm{H}_{2} \mathrm{PtCl}_{6}+1.1 \mathrm{M}$ $\mathrm{HCl}$ solution, washed with $0.5 \mathrm{M} \mathrm{H}_{2} \mathrm{SO}_{4}$, and subsequently placed in another cell containing only $0.5 \mathrm{M} \mathrm{H}_{2} \mathrm{SO}_{4}$ to obtain the 


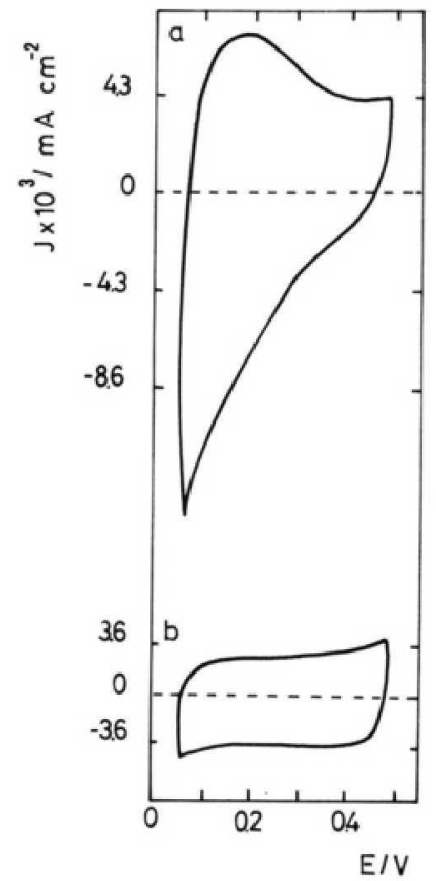

Figure 3. (a) Voltammogram obtained in $0.5 \mathrm{M} \mathrm{H}_{2} \mathrm{SO}_{4}$ at $0.1 \mathrm{~V} \mathrm{~s}^{-1}$ between 0.05 and $0.5 \mathrm{~V}$ on a HOPG electrode partially coated with electrodeposited $\mathrm{Pt}$ at $0.62 \mathrm{~V}$ and $25^{\circ} \mathrm{C}$. (b) Voltammogram obtained on a clean HOPG electrode under the same conditions.

voltammogram between 0.05 and $0.5 \mathrm{~V}$ at $0.1 \mathrm{~V} \mathrm{~s}^{-1}$. These voltammograms (Figure 3a) have always shown the same voltammetric response for $\mathrm{H}$ adatom electrosorption already reported for the Pt electrodispersed on C electrodes, ${ }^{17}$ in contrast to the blank run on clean HOPG (Figure 3b). The increase in the deposition time and that of $q_{\mathrm{c}}$ result in an increase of the $\mathbf{H}$ adatom electrosorption charge. Therefore, a fraction of $q_{\mathrm{c}}$ derived from the current transients (Figure $2 a$ ) should be attributed to the own electrodeposition of $\mathrm{Pt}$ on $\mathrm{C}$.

3.3. SEM Imaging. SEM images of Pt electrodeposits grown at $E_{\mathrm{d}}=0.62 \mathrm{~V}\left(q_{\mathrm{c}} \simeq 2.5 \mathrm{mC} \mathrm{cm}^{-2}\right)$ (Figure 4a) show the formation of small Pt crystallites ( $200 \mathrm{~nm}$ size) randomly distributed on the HOPG surface. SEM images after prolonged electrolysis also reveal large irregular Pt agglomerates of about $10 \mu \mathrm{m}$ in size (Figure 4b). These agglomerates show terraces, subterraces, borders, and kinks; these geometry features show $60^{\circ}, 120^{\circ}$, and, to a less extent, $90^{\circ}$ angles.

3.4. STM Imaging. The STM image $\left(380 \times 380 \mathrm{~nm}^{2}\right)$ of a Pt electrodeposit grown at $E_{\mathrm{d}}=0.675 \mathrm{~V}$ for $t=60 \mathrm{~s}\left(q_{\mathrm{c}}=1 \mathrm{mC}\right.$ $\mathrm{cm}^{-2}$ ) depicts the initial stages of Pt electrodeposition (Figure 5a). This image displays a discontinuous deposit formed by agglomerates with an orderly although complex structure. One can observe incomplete triangular crystallites and rowlike patterns following well-defined directions with angles of $30^{\circ}, 60^{\circ}, 90^{\circ}$. Both the incomplete crystallites and the rows are made of loosely bound rounded nuclei of about $2-3 \mathrm{~nm}$ in size (Figure $5 \mathrm{~b}$ ). A small number of individual nuclei can also be distinguished on flat HOPG domains. Agglomerates form preferentially at HOPG surface defects. This can be more clearly seen in a 3D image (arrow in Figure 5c) revealing that the agglomerates shown in Figure $5 b$ have been formed at a HOPG step edge. Furthermore, the STM images at a higher magnification $\left(73 \times 73 \mathrm{~nm}^{2}\right)$ depict rows of rounded nuclei (2-3 nm size) growing on top of terraces (Figure 5d). Due to the flatness and inertness of graphite (0001) cleavage plane, the imaged structures can be conclusively attributed to Pt electrodeposited on the substrate.

A $700 \times 700 \mathrm{~nm}^{2}$ STM image after Pt electrodeposition at $E_{\mathrm{d}}$ $=0.675 \mathrm{~V}\left(q_{\mathrm{c}}=3.0 \mathrm{mC} \mathrm{cm}^{-2}\right)$ shows a large crystal surface with a number of flat terraces and steps (Figure 6). In this case the steps height ranges from 1 to $10 \mathrm{~nm}$ with an overall height

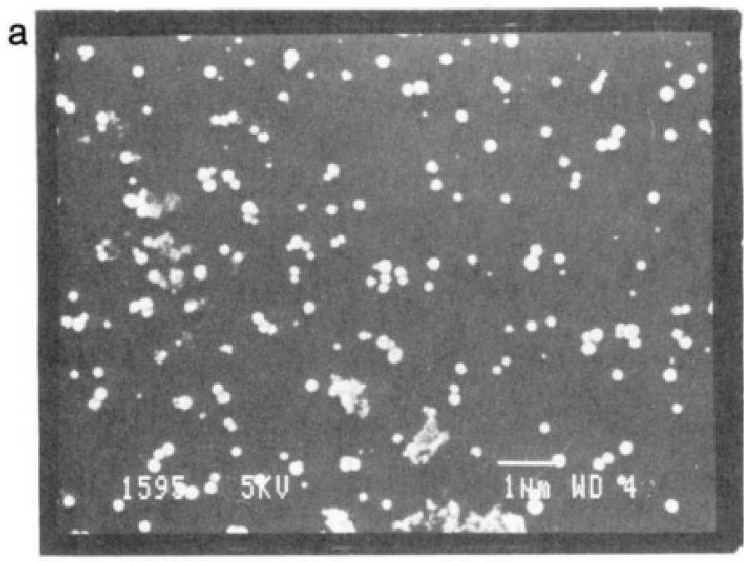

b

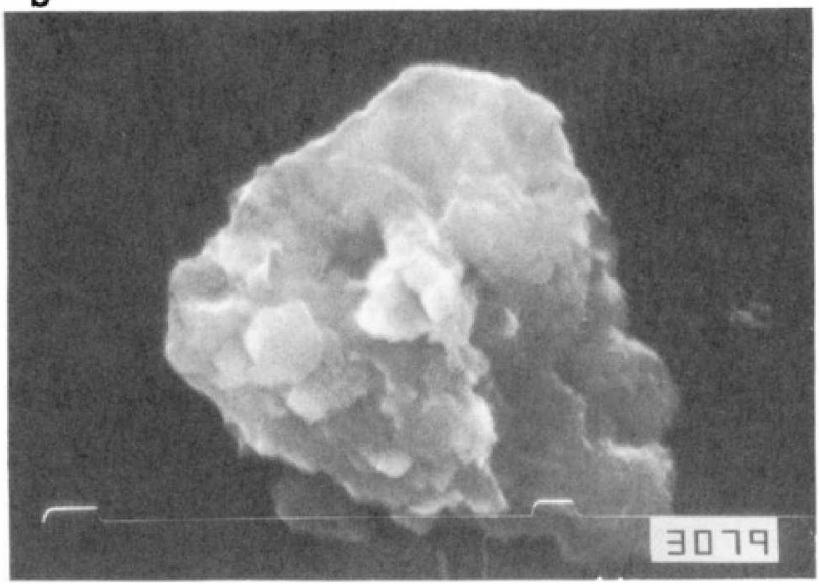

Figure 4. SEM micrographs of Pt electrodeposits on HOPG produced from aqueous $3.86 \times 10^{-2} \mathrm{M} \mathrm{H}_{2} \mathrm{PtCl}_{6}+1.1 \mathrm{M} \mathrm{HCl} \mathrm{at} E=0.62 \mathrm{~V} ; q_{\mathrm{c}}=$ $2.5 \mathrm{mC} \mathrm{cm}^{-2}$. (a) The horizontal bar indicates the $1=\mu \mathrm{m} \mathrm{scale}$; (b) the bar indicates $10 \mu \mathrm{m}$.

difference of $26 \mathrm{~nm}$. The step directions define $90^{\circ}$ angles, and the edges of some steps are rather irregular with large number of kinks. The rough topography of a $\mathrm{Pt}$ agglomerate surface such as that shown in Figure $4 \mathrm{~b}$ indicates that the imaged structure corresponds to an advanced stage of Pt growth rather than to the flat HOPG substrate.

STM images of Pt electrodeposits prepared at $E_{\mathrm{d}}=0.62 \mathrm{~V}$ and $1 \mathrm{mC} \mathrm{cm}^{-2}<q_{\mathrm{c}}<2 \mathrm{mC} \mathrm{cm}^{-2}$ were also obtained. For $q_{\mathrm{c}}=1.5$ $\mathrm{mC} \mathrm{cm}^{-2}$ the STM image (Figure 7) shows large Pt agglomerates of about $900 \mathrm{~nm}$ in size formed by triangular and flat crystallites. These crystallites resemble those shown in Figure 5, although in this case the Pt crystals appear somewhat more compact and the rounded small nuclei previously described (Figure 5a,b,d) are no longer distinguishable as individual clusters. It should be noted that the largest Pt agglomerates are located at HOPG steps (Figure 7) similarly to the small agglomerates formed at earlier stages of growth (Figure 5c). However, Pt agglomerates at advanced growth stages become higher than the HOPG steps so that the Pt deposit spreads over the lower and the upper HOPG terraces (Figure 7). These large agglomerates can also be related to Pt agglomerates of about $1 \mu \mathrm{m}$ in size shown in Figure 4a.

STM images resulting from Pt electrodeposits produced at $E_{\mathrm{d}}$ $=0.62 \mathrm{~V}$ and $q_{\mathrm{c}}=2.0 \mathrm{mC} \mathrm{cm}-2$ correspond to compact Pt crystallites with triangular terraces (Figure 8) which are similar to those previously described. The overlapping of these terraces generates a large number of parallel steps of about $100 \mathrm{~nm}$ in length. There is a clear predominance of $60^{\circ}$ angles in these images.

Atomic resolution imaging was also attempted on top of the terraces of flat triangular Pt crystallites and on flat areas surrounding Pt crystals. The current mode to minimize drift 

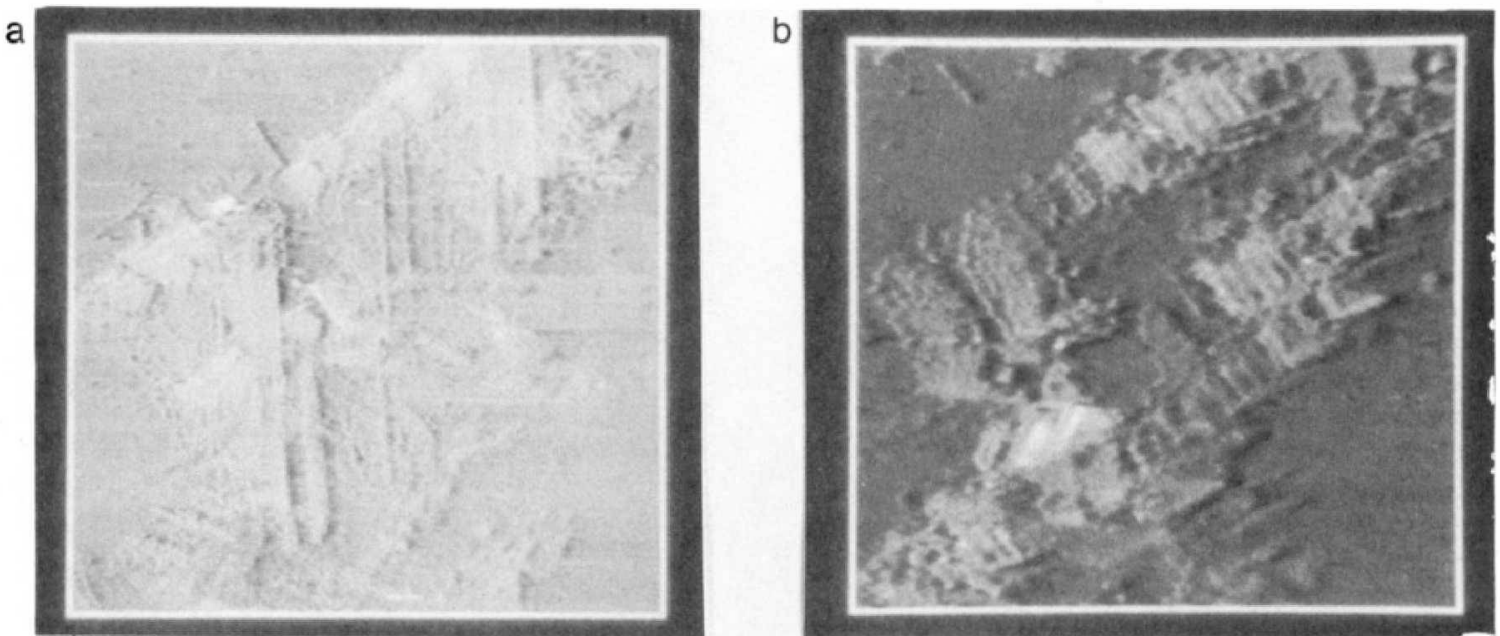

C
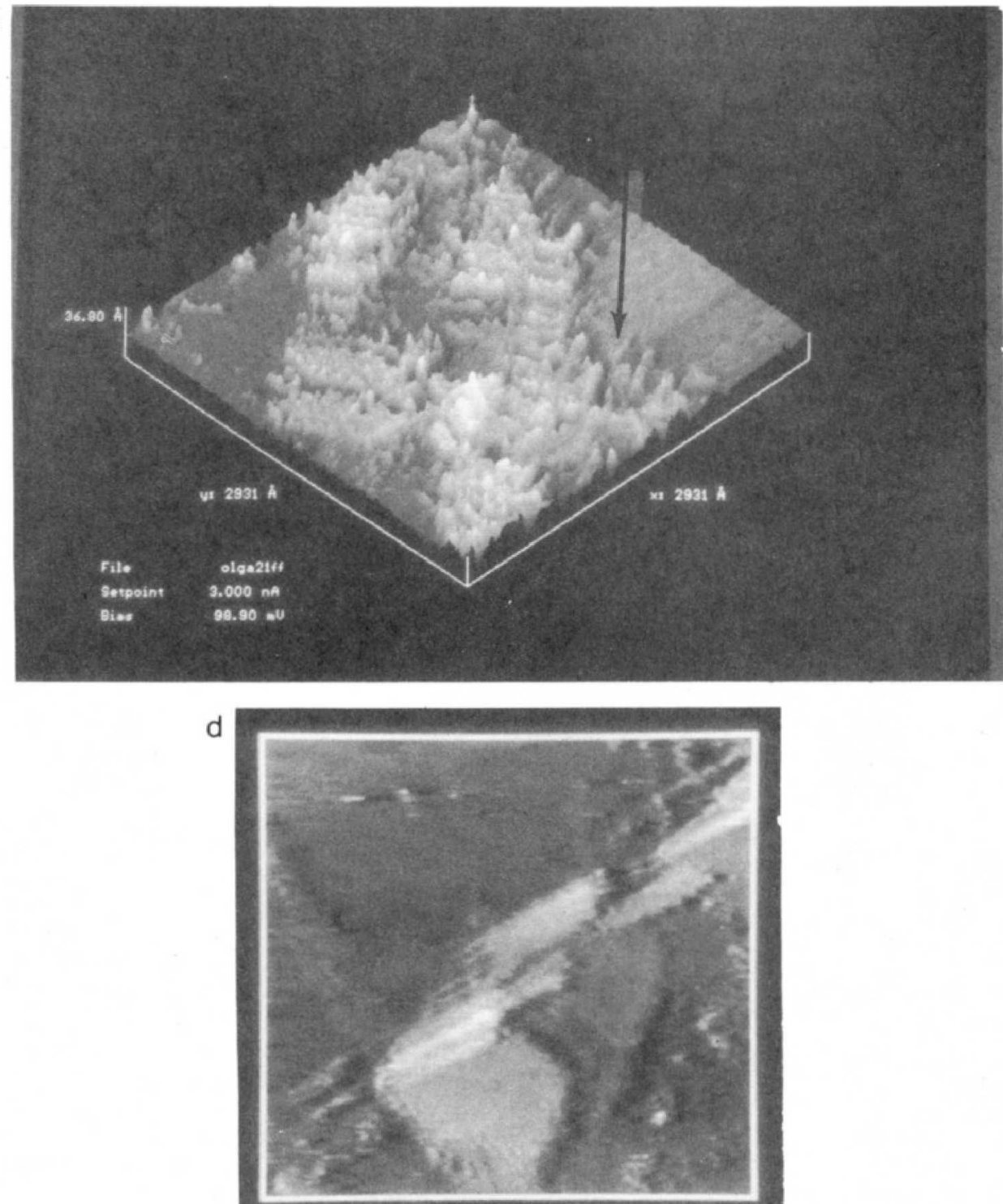

Figure 5. STM images of a Pt electrodeposit grown on HOPG from aqueous $3.86 \times 10^{-2} \mathrm{M} \mathrm{H}_{2} \mathrm{PtCl}_{6}+1.1 \mathrm{M} \mathrm{HCl}$ at $E_{\mathrm{d}}=0.675 \mathrm{~V}$ for $t=60 \mathrm{~s} ; q_{\mathrm{c}}$ $=1 \mathrm{mC} \mathrm{cm}^{-2}$. (a) $380 \times 380 \mathrm{~nm}^{2}$, top view; (b) $293 \times 293 \mathrm{~nm}^{2}$, top view; (c) 3D STM image of the STM top view shown in (b); (d) $73 \times 73 \mathrm{~nm}{ }^{2}$, top view.

effects was used in these cases. The STM image obtained on a flat area located at about $20 \mathrm{~nm}$ from a Pt crystal edge showed a hexagonal array of atoms with the nearest-neighbor distance $d=0.24 \pm 0.02 \mathrm{~nm}$, as expected for HOPG when three out of six $\mathrm{C}$ atoms are imaged. These results prove that at the early stages of 3D Pt nuclei growth the Pt monolayer is still incomplete.
The STM image taken on a Pt terrace also showed a hexagonal array of atoms, the distance between the nearest-neighbor atoms estimated along the $x$ direction was $d=0.28 \pm 0.03 \mathrm{~nm}$, a figure which would be consistent with the crystallite surface structure of $\mathrm{Pt}(111)$. However, taking into account the presence of $\mathrm{C}$ on $\mathrm{Pt}$ in air, this result could be due to corrugation imposed on the 


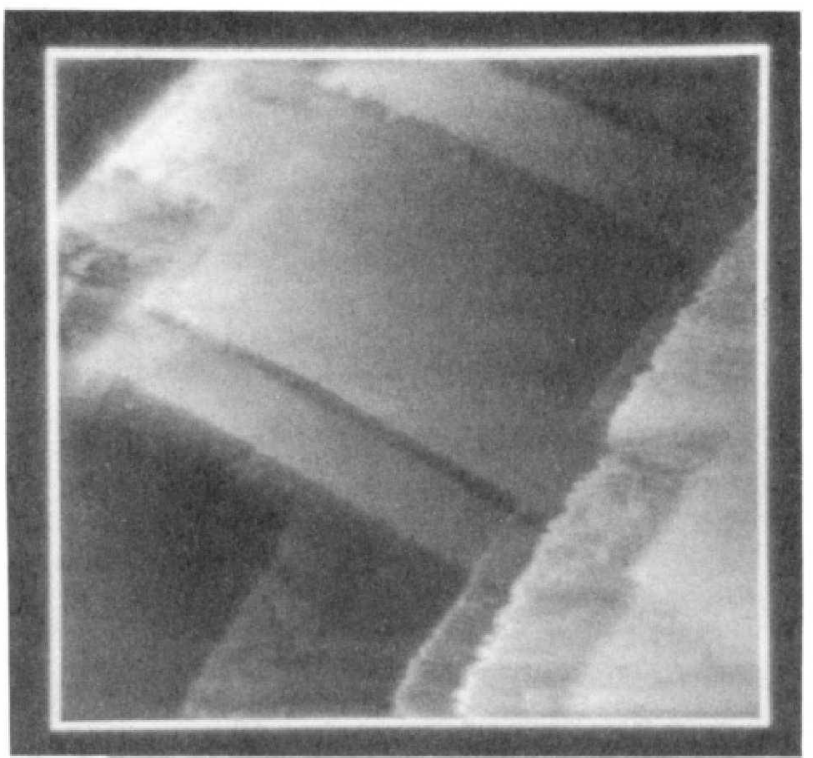

Figure 6. A $700 \times 700 \mathrm{~nm}^{2}$ STM image (top view) of a Pt electrodeposit formed on HOPG from aqueous $3.86 \times 10^{-2} \mathrm{M} \mathrm{H}_{2} \mathrm{PtCl}_{6}+1.1 \mathrm{M} \mathrm{HCl}$ at $E_{\mathrm{d}}=0.675 \mathrm{~V} ; q_{\mathrm{c}}=3.0 \mathrm{mC} \mathrm{cm}^{-2}$.
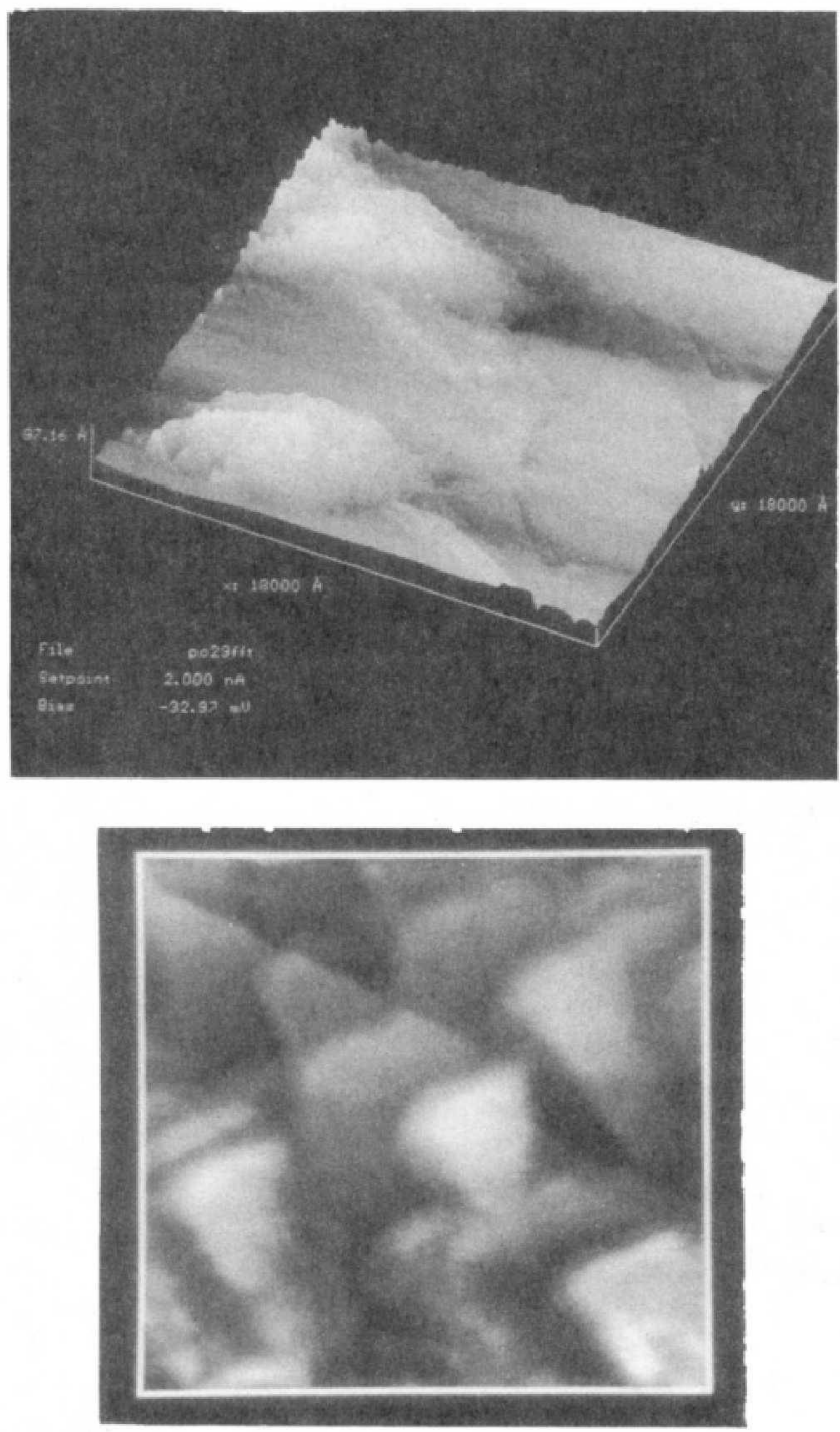

Figure 7. $1800 \times 1800 \mathrm{~nm}^{2}$ and $400 \times 400 \mathrm{~nm}^{2} 3 D$ STM images for a Pt electrodeposit produced on HOPG from aqueous $3.86 \times 10^{-2} \mathrm{M} \mathrm{H}_{2^{-}}$ $\mathrm{PtCl}_{6}+1.1 \mathrm{M} \mathrm{HCl}$ at $E_{\mathrm{d}}=0.62 \mathrm{~V} ; q_{\mathrm{c}}=1.5 \mathrm{mC} \mathrm{cm}^{-2}$.

contaminant layer by the underlying substrate or to tip poking through the $\mathrm{C}$ layer. $\mathrm{C}$ atoms on metals imaged by STM at a

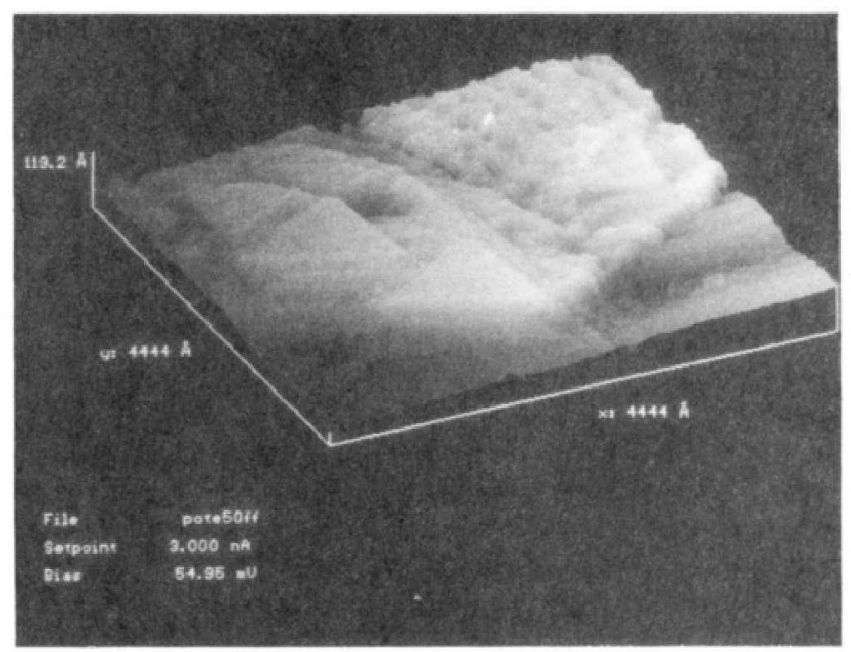

Figure 8. A $444 \times 444 \mathrm{~nm}^{2} 3 \mathrm{DSTM}$ image resulting for Pt electrodeposits produced on $\mathrm{HOPG}$ from aqueous $3.86 \times 10^{-2} \mathrm{M} \mathrm{H}_{2} \mathrm{PtCl}_{6}+1.1 \mathrm{M} \mathrm{HCl}$ at $E_{\mathrm{d}} \equiv 0.62 \mathrm{~V} ; q_{c} \equiv 2.0 \mathrm{mC} \mathrm{cm}^{-2}$.

coverage lower than a monolayer imaged by STM appear as isolated protrusions which introduce apparent vertical displacements in the neighbor metal atoms due to modifications in the electronic structure of the substrate. ${ }^{25}$

\section{Discussion}

4.1. Growth Characteristics and Morphologies of Pt Deposits on HOPG. In agreement with SEM micrographs, the lowresolution STM imaging of Pt deposits grown within the potential window used in this work is characterized by a number of separate Pt agglomerates and large bare HOPG surface domains. On the other hand, STM imaging at the nanometer level obtained at the early stages of Pt electrodeposit growth reveals the presence of small rounded nuclei with $2-3 \mathrm{~nm}$ average size. These morphologies of Pt electrodeposits on HOPG are similar to those recently reported for $\mathrm{Pt}$ deposits grown either from vapor or by chemical impregnation on HOPG. ${ }^{13}$ The same growth sequence from hemispherical nuclei to agglomerates has been observed for the growth of $\mathrm{Ag}$ deposits on HOPG, ${ }^{9}$ although in this case the average size of $\mathrm{Ag}$ nuclei was about $10-20 \mathrm{~nm}$, i.e., a size larger than that found for Pt nuclei. This size difference is consistent with the fact that $D_{\mathrm{s}}$, the surface diffusion coefficient of Ag atoms, at room temperature $\left(D_{\mathrm{s}} \cong 10^{-11} \mathrm{~cm}^{2} \mathrm{~s}^{-1}\right)^{27}$ is several orders of magnitude higher than that of $\mathrm{Pt}\left(D_{\mathrm{s}} \cong 10^{-18} \mathrm{~cm}^{2} \mathrm{~s}^{-1}\right) .28$

The small hemispherical Pt nuclei display ordered arrays following mainly the HOPG crystallographic directions and leading to geometric structures which apparently behave as precursors of large, compact, and flat triangularly-shaped $\mathrm{Pt}$ crystallites. These crystallites can be better observed at advanced stages of Pt electrodeposit growth (Figure 8). These crystallites and the rounded nuclei form large agglomerates with irregular and rough surfaces.

STM imáges proves the nonuniform characteristics of Pt layers produced from Pt electrodeposition on HOPG. This fact is consistent with the voltammetric results for $\mathrm{H}$ adatom electrosorption processes on carbon electrodes partially covered by Pt deposits. ${ }^{29}$ The heights of the $\mathrm{H}$ adatom electrosorption current peaks increase according to the amount of electrodeposited $\mathrm{Pt}$, and those peaks keep the characteristics of those resulting for Pt deposits formed by particles with an average diameter lower than $1 \mu \mathrm{m} .{ }^{20}$

The atomic level STM imaging of the HOPG electrode surface partially covered by $\mathrm{Pt}$ aggregates reveals no traces of $\mathrm{Pt}$ at bare HOPG surface domains between Pt crystallites. This fact contrasts with previous observations of Pt electrodeposition on vitreous carbon from $10^{-2} \mathrm{M} \mathrm{K}_{2} \mathrm{PtCl}_{4}$ in aqueous $\mathrm{H}_{2} \mathrm{SO}_{4}$. Accordingly, 3D growth starts only when the Pt monolayer deposit has been completed. ${ }^{29}$ Otherwise, the topographic sequences 
resulting from Pt electrodeposition on HOPG from aqueous 3.86 $\times 10^{-2} \mathrm{M} \mathrm{H}_{2} \mathrm{PtCl}_{6}+1.1 \mathrm{M} \mathrm{HCl}$ in the $0.620-0.675$ - $\mathrm{V}$ range are consistent with a Volmer type growth mechanism. ${ }^{1}$

4.2. The Possible Mechanism Related to the Early Stages of Pt Electrodeposition on HOPG from $\mathrm{H}_{2} \mathrm{PtCl}_{6}$ Aqueous Solution. This work allows the establishment of a relationship between $\mathrm{Pt}$ growth topography and the kinetics of the early stages of $\mathrm{Pt}$ electrodeposition on HOPG, on the basis of STM and electrochemical data.

Previous studies of $\mathrm{Pt}$ electrodeposition on $\mathrm{C}$ electrodes ${ }^{18,19}$ have shown that the current plateau $C_{1}$ could be attributed to the electroreduction of $\mathrm{PtCl}_{6}{ }^{2-}$ to $\mathrm{PtCl}_{4}{ }^{2-}$ species according to the reaction

$$
\mathrm{PtCl}_{6}{ }^{2-}+2 \mathrm{e}^{-}=\mathrm{PtCl}_{4}{ }^{2-}+2 \mathrm{Cl}^{-}
$$

This reaction occurs under diffusion control for applied potentials lower than the corresponding equilibrium potential, $E^{\circ}{ }_{1}=0.726$ $\mathrm{V}$. From the thermodynamic standpoint, in the potential range of plateau $\mathrm{C}_{1}$, the following reaction

$$
\mathrm{PtCl}_{4}{ }^{2-}+2 \mathrm{e}^{-}=\mathrm{Pt}(0)+4 \mathrm{Cl}^{-}
$$

could also occur as the equilibrium potential of reaction 2 is $E^{\circ}{ }_{2}$ $=0.758 \mathrm{~V}$ (vs NHE) at $25^{\circ} \mathrm{C},{ }^{30}$ However, under these circumstances the contribution of reaction 2 could be neglected as, for instance, the rate of this reaction in $1 \mathrm{M} \mathrm{NaCl}$ is 2 orders of magnitude lower than that of reaction $1 .{ }^{31}$ Furthermore, in aqueous $1 \times 10^{-3} \mathrm{M} \mathrm{PtCl}_{4}{ }^{2-}$-reaction 2 takes place only at potentials more negative than $0.53 \mathrm{~V}$, i.e., in the potential range of peak $\mathrm{C}_{2}{ }^{19}$ Finally, a disproportionation of $\mathrm{Pt}(\mathrm{II})$ into $\mathrm{Pt}(0)$ and $\mathrm{Pt}$ (IV) species may occur at $\mathrm{HOPG}$ in $\mathrm{H}_{2} \mathrm{PtCl}_{6}$ solution according to

$$
2 \mathrm{PtCl}_{4}{ }^{2-}=\mathrm{Pt}(0)+\mathrm{PtCl}_{6}{ }^{2-}+2 \mathrm{Cl}^{-}
$$

The equilibrium constant of reaction 3 at $25^{\circ} \mathrm{C}$ is about 10,32 although this reaction proceeds very slowly, as it takes $500 \mathrm{~h}$ at $60^{\circ} \mathrm{C}$ to come to equilibrium. ${ }^{21}$ The kinetics of $\mathrm{Pt}$ electrodeposition on different carbon electrodes in $\mathrm{H}_{2} \mathrm{PtCl}_{6}$ aqueous solutions were mainly considered on the basis of reactions 1-3 neglecting the intrinsic heterogeneity of the electrode surface. These results, however, can hardly be explained exclusively in terms of this rather simple reaction pathway.

The analysis of STM and electrochemical kinetic data presented in sections 3.2 and 3.4 allows us to advance a more complete mechanistic approach for the early stages of Pt electrodeposition on HOPG from aqueous $\mathrm{H}_{2} \mathrm{PtCl}_{6}$ solutions. The STM data show two distinguishable reaction domains, namely, large defect-free HOPG domains where no Pt can be deposited and small defectcontaining surface domains where Pt electrodeposition takes place.

Electrochemical data allow us to express $j$, the overall cathodic current as the sum of two contributions:

$$
j=j_{\mathrm{d}}+j_{\infty}
$$

where $j_{\mathrm{d}}$ is a diffusion current contribution and $j_{\infty}$ is the constant current contribution at $t_{\mathrm{o}}$ for constant $E_{\mathrm{d}}$.

Let us first consider the origin of $j_{\mathrm{d}}$ on the basis of the SandCottrel plot (Figure 2a) together with the fact that the stable Pt-containing ionic species in $\mathrm{H}_{2} \mathrm{PtCl}_{6}$ aqueous solution in an excess of $\mathrm{HCl}$ are $\mathrm{PtCl}_{6}{ }^{2-}$ (or $\mathrm{HPtCl}_{6}{ }^{-}$) and $\mathrm{PtCl}_{4}{ }^{2-}$ (or $\mathrm{HPtCl}_{4}{ }^{-}$) complex ions with an octahedral and a square planar configuration, respectively. ${ }^{21}$ In principle, the value of $c$, the concentration of the diffusing electroactive species in the solution, can be calculated through the equation

$$
S=z F D^{1 / 2} c / \pi^{1 / 2}
$$

where $z$ and $F$ have the usual meanings. Using the diffusion coefficients of $\mathrm{PtCl}_{4}{ }^{2-}\left(D=2.2 \times 10^{-5} \mathrm{~cm}^{2} \mathrm{~s}^{-1}\right)$ and $\mathrm{PtCl}_{6}{ }^{2-}(D$ $\left.=4.5 \times 10^{-6} \mathrm{~cm}^{2} \mathrm{~s}^{-1}\right)$ species, in all cases it results that the values of $c$ derived from eq 5 are systematically 1 order of magnitude lower than that of $\mathrm{PtCl}_{6}{ }^{2-}$ ions in the solution. Therefore, as $\mathrm{H}_{2} \mathrm{PtCl}_{6}$ is completely dissociated under the conditions of these experiments, ${ }^{21}$ one can discard the possibility that the $\mathrm{H}_{2} \mathrm{PtCl}_{6}$ electroreduction reaction is controlled by the diffusion of either $\mathrm{H}_{2} \mathrm{PtCl}_{6}$ or $\mathrm{PtCl}_{6}{ }^{2-}$ species from the solution side toward the electrode surface. Otherwise, the values of $c$ estimated from eq 5 increase with $E_{\mathrm{d}}$ as predicted by a Nernst type equation for a monoelectronic reaction with a slope $0.059 \mathrm{~V} /$ decade at $298 \mathrm{~K}$. The same conclusion can be reached from the current transients found in $\mathrm{K}_{2} \mathrm{PtCl}_{4}$-containing solutions.

The above results suggest that the kinetically significant diffusing species originates from a preceding one-electron-transfer step involved in the global electrochemical reaction 1 . Then, the kinetics of the reaction would involve as rate-determining step the diffusion of a product from the electrode surface outward. Correspondingly, the following reactions can be advanced:

$$
\mathrm{PtCl}_{6}{ }^{2-}(\mathrm{sol})+\mathrm{e}^{-}=\mathrm{PtCl}_{5}{ }^{2-}(\mathrm{HOPG})+\mathrm{Cl}^{-}
$$

and

$$
\mathrm{PtCl}_{5}{ }^{2-} \text { (HOPG) }=\mathrm{PtCl}_{5}{ }^{2-} \text { (sol) }
$$

Besides, the $\mathrm{PtCl}_{5}{ }^{2-}$ species formed through reactions $6 \mathrm{a}$ and $6 \mathrm{~b}$ can take part in a process such as

$$
2 \mathrm{PtCl}_{5}{ }^{2-} \text { (sol) }=\mathrm{PtCl}_{4}{ }^{2-} \text { (sol) }+\mathrm{PtCl}_{6}{ }^{2-} \text { (sol) }
$$

Reaction $6 \mathrm{a}$ corresponds to the reversible discharge of the $\mathrm{PtCl}_{6}{ }^{2-}$ complex ion yielding $\mathrm{PtCl}_{5}{ }^{2-}$ species which diffuses outward. The appearance of Pt(III) species in this reaction has been already discussed and justified in earlier works. ${ }^{33}$ Reaction $6 \mathrm{c}$ corresponds to the disproportionation of $\mathrm{PtCl}_{5}{ }^{2-}$ species into $\mathrm{Pt}(\mathrm{II})$ and $\mathrm{Pt}$ (IV) complex ions.

From the reversible reactions $6 \mathrm{a}$ and $6 \mathrm{~b}$, it results

$$
\left.E=E^{\infty}-(R T / F) \log \left[\mathrm{PtCl}_{5}{ }^{2-}\right]\left[\mathrm{Cl}^{-}\right] / \mathrm{PtCl}_{6}{ }^{2-}\right]
$$

where the brackets denote the concentration of the different species, and $E^{\prime}$ is the formal standard equilibrium potential of reaction $6 \mathrm{a}$ for unit concentration of the reacting species. According to eq 7, the concentration of $\mathrm{PtCl}_{5}{ }^{2-}$ species fits a Nernst equation with the $R T / F$ slope as found experimentally. Then, the dependence of both $S$ and $c$ on $E_{\mathrm{d}}$, and the fact that the slope of the $j$ vs $t^{-1 / 2}$ plot becomes independent of the $\mathrm{K}_{2} \mathrm{PtCl}_{4}$ concentration, would indicate that the kinetics of reaction 1 is determined by the diffusion of $\mathrm{PtCl}_{5}{ }^{2-}$ ions from the electrode surface outward (reaction $6 \mathrm{~b}$ ).

Let us consider now the reactions related to the quasi-steady potential-dependent current $j_{\infty}$. This current can be related to the electrodeposition of Pt which, according to STM imaging, takes place at HOPG defects (HOPGD). The linear $\log j_{\infty}$ vs $E_{\mathrm{d}}$ plot with a slope close to $R T / F$ whose validity extends within the potential range of $C_{1}$ and becomes independent of the $K_{2}-$ $\mathrm{PtCl}_{4}$ concentration, suggests the possibility that the initial electrodeposition of $\mathrm{Pt}$ at HOPGD involves a surface reaction kinetic control. Then, it appears reasonable to extend the kinetic analysis discussed above to the reactions occurring at HOPGD sites. Then, this can be written

$$
\left.\mathrm{PtCl}_{6}{ }^{2-} \text { (sol) }+\mathrm{e}^{-}=\mathrm{PtCl}_{5}{ }^{2-} \text { (HOPGD }\right)+\mathrm{Cl}^{-}
$$

followed by the disproportionation reaction

$$
\begin{aligned}
2 \mathrm{PtCl}_{5}{ }^{2-}(\mathrm{HOPGD})= & 0.5 \mathrm{Pt}(\mathrm{HOPGD})+ \\
& 1.5 \mathrm{PtCl}_{6}{ }^{2-}(\mathrm{HOPGD})+\mathrm{Cl}^{-}
\end{aligned}
$$

The latter reaction yielding $\mathrm{Pt}$ formation at HOPGD can be justified considering that the interaction between the HOPGD and the $\mathrm{PtCl}_{5}{ }^{2-}$ intermediates should increase as the electron density at HOPGD exceeds that of HOPG flat domains. Then, 
the adsorbed intermediates at HOPGD produce $\mathrm{Pt}(0)$ through the disproportionation reaction $8 \mathrm{~b}$ as the rate-determining step.

Further kinetic and mechanistic features can be derived from $j_{\infty}$ values. Thus, providing that the rates of the fast reversible reaction $8 \mathrm{a}$ in both directions are similar, $\theta$, the degree of coverage of HOPGD sites by the $\mathrm{PtCl}_{5}{ }^{2-}$ intermediates, under Temkin isotherm conditions, ${ }^{34}$ can be expressed as

$$
(\theta / 1-\theta) \exp [-r \theta]=K\left[\mathrm{PtCl}_{6}{ }^{2-}\right]\left[\mathrm{Cl}^{-}\right]^{-1} \exp \left(-F \eta_{\mathrm{c}} / R T\right)
$$

where $K$ is the pseudoequilibrium constant of reaction $8 \mathrm{a}$, i.e., the ratio of the rate constants of reactions $8 a$ in the forward and backward direction, and $r$ is the change rate of the apparent standard free energy of adsorption with coverage. Likewise, disregarding the influence of the preexponential term involving $\theta$, the rate of reaction $8 \mathrm{~b}$ given in terms of $j_{\infty}$ becomes

$$
j_{\infty} \cong F k \exp (2 \gamma r \theta / R T)
$$

where $k$ is the specific rate constant of reaction $8 \mathrm{~b}$ and $\gamma r$ is the change rate of the apparent standard free energy of activation with coverage for the desorption process. For an activated adsorption process $\gamma=0.5$, and since in the Temkin isotherm $r \theta$ depends linearly on the applied potential, eq 10 becomes

$$
j_{\infty} \propto \exp \left(-F \eta_{\mathrm{c}} / R T\right)
$$

Equation 11 satisfies the Tafel relationship illustrated in Figure $2 e$.

It should be noted that the proposed reaction pathway for the electrodeposition of $\mathrm{Pt}$ at HOPGD explains the preferred nucleation of $\mathrm{Pt}$ only at these sites, and the development of a deposit morphology which closely resembles that obtained for $\mathrm{Pt}$ deposits resulting from the chemical reduction of $\mathrm{H}_{2} \mathrm{PtCl}_{6}$ on carbon substrates. ${ }^{13}$ Furthermore, reaction 8 b should be favored at HOPGD due to the high electronic density at these sites and to the fact that the activity of Pt on the entire HOPG surface is less than 1 at least while the Pt layer is incomplete.

After nucleation at the HOPG defects, the growth of small $\mathrm{Pt}$ nuclei (1-2 nm in size) may also occur through reactions $8 \mathrm{a}$ and $8 \mathrm{~b}$ due to the high specific reactivity of nanometer size metal particles. The formation of large and flat crystallites should involve sintering of small particles. ${ }^{28}$

The Pt electrodeposition on HOPG also occurs at potentials located in the region of peak $\mathrm{C}_{2} .{ }^{19}$ Although the study of this process is beyond the scope of this work, it should be noted that at high cathodic potentials the overall reaction probably goes directly through the discharge of the complex ions under diffusion control, as given by reaction 2 together with the following reaction:

$$
\mathrm{PtCl}_{6}{ }^{2-}+4 \mathrm{e}^{-}=\mathrm{Pt}(\mathrm{s})+6 \mathrm{Cl}^{-}
$$

Finally, reactions 2 and 12 proceed simultaneously with the $H$ atom electrosorption on $\mathrm{Pt}$ followed by the hydrogen evolution reaction in the potential range of peak $C_{3}$.

\section{Conclusions}

(i) The early stages of Pt electrodeposition on HOPG involve nucleation and 3D growth at surface defects, particularly at step edges of the substrate, as observed through STM. The 3D growth of $\mathrm{Pt}$ starts before a $\mathrm{Pt}$ monolayer is formed. A Volmer type growth mechanism appears consistent with the STM data.

(ii) Rounded Pt clusters of about $2 \mathrm{~nm}$ in size are formed at low cathodic potentials and low Pt electrodeposition charge densities. These clusters show a trend to form rows of nuclei aligned in well-defined directions and further yielding orderly 3D structures.

(iii) Compact Pt crystals with flat terraces are formed by increasing the applied cathodic potential and the Pt electrodeposition charge density. (iv) Pt electrodeposition at HOPG defects in the potential range of plateau $\mathrm{C}_{1}$ can be described as a reaction mechanism involving the electroreduction of $\mathrm{Pt}$ (IV) to $\mathrm{Pt}$ (III) species, followed by the $\mathrm{Pt}(\mathrm{III})$ disproportionation reaction into $\mathrm{Pt}(0)$ and $\mathrm{Pt}(\mathrm{IV})$. These reactions occur simultaneously with the $\mathrm{Pt}$ (IV) to $\mathrm{Pt}$ (II) diffusioncontrolled electroreduction at HOPG.

Acknowledgment. This work was in part financially supported by the Consejo Nacional de Investigaciones Cientificas y Técnicas (CONHCET) of Argentina.

\section{References and Notes}

(1) Budevski, E. B. In Comprehensive Treatise of Electrochemistry; Conway, B. E., Bockris, J. O'M, Yeager, E., Khan, S. U. M., White, R. E., Eds.; Plenum Press: New York, 1983; Vol. 7, p 399.

(2) Green, M. P.; Hanson, K. J.; Carr, R.; Lindau, I. J. Electrochem. Soc. 1990, 137, 3493.

(3) Magnussem, O. M.; Hotlos, J.; Nichols, R. J.; Kolb, D. M.; Behm, R. J. Phys. Rev. Lett. 1990, 64, 2929. 3677 .

(4) Yau, S. L.; Vitus, C. M.; Schard, B. C. J. Am. Chem. Soc. 1968, 112 ,

(5) Magnussem, O. M.; Hotlos, J.; Beitel, G.; Kolb, D. M.; Behm, R. J. J. Vac. Sci. Technol. B 1991, 9, 969. 452 .

(6) Szklarczyk, M.; Bockris, J. O'M. J. Electrochem. Soc. 1990, 137,

(7) Nichols, R. J.; Kolb, D. M.; Behm, R. J. J. Electroanal. Chem. 1991, $313,109$.

(8) Sonnenfeld, R.; Schard, B. C. Appl. Phys. Lett. 1986, 49, 1172.

(9) Vázquez, L.; Hernández-Creus, A.; Carro, P.; Ocón, P.; Herrasti, P.; Palacio, C.; Vara, J. M.; Salvarezza, R. C.; Arvia, A. J. J. Phys. Chem., in press.

(10) Stonehart, P.; Kinoshita, K.; Bett, J. A. S. Proc. Electrocatalysis; Breiter, M. W., Ed.; The Electrochemical Society: Princeton, NJ, 1984; p 275.

(11) Lee, S.; Permana, H.; Simon Ng, K. Y.J. Vac. Sci. Technol. B 1992, 10,561 .

(12) Yeung, K. L.; Wolf, E. E. J. Catal. 1992, 135, 13.

(13) Yeung, K. L.; Wolf, E. E.; Duman, J, G. J. Vac. Sci. Technol. B 1991 , 9,1197

(14) Gillet, M. Surf. Sci. 1977, 67, 139.

(15) Gao, S.; Schmidt, L. D. J. J. Catal. 1989, 115, 356.

(16) Wang, T.; Lee, C.; Schmidt, L. D. Surf. Sci. 1981, 163, 181.

(17) Egli, W. A.; Triaca, W. E.; Arvia, A. J. Appl. Surf. Sci., in press.

(18) Shimazu, K.; Weisshaar, D.; Kuwana, T. J. Electroanal. Chem. 1984, $223,223$.

(19) Georgolios, N.; Jannakoudakis, D.; Karabinas, P. J. Electroanal. Chem. 1989, 264, 235.

(20) Giles, R. D.; Harrison, J. A.; Thirsk, H. R. J. Electroanal. Chem. $1969,20,47$.

(21) Feltham, A. M.; Spiro, M. Chem. Rev. 1971, 71, 177 and references therein.

(22) Obretenov, W.; Höpfner, M.; Lorenz, W. J.; Budevski, E.; Staikov, G.; Siegenthaler, H. Surf. Sci. 1992, 271, 191.

(23) Maurice, V.; Marcus, P. Surf. Sci. 1992, 262, L59.

(24) Angerstein-Kozlowska, $H$. In Comprehensive Treatise of Electrochemistry; Yeager, E., Bockris, J. O'M., Conway, B. E., Sarangapani, S., Eds.; Plenum Press: New York, 1984; Vol. 9, p 22.

(25) Behm, R. J. In Scanning Tunneling Microscopy and Related Methods; Behm, R. J., García, N., Rohrer, H. Eds.; NATO ASI Series, 1989.

(26) Chiang, S.; Chambliss, D. D.; Hallmark, V. M.; Wilson, R. J.; Wöll, Ch. In The Structure of Surfaces III; Tong, S. Y., Van Hove, M. A., Takayanagi, K., Xie, X. D., Eds.; Springer-Verlag: Berlin, 1991; p 204.

(27) Gimzewki, J. K.; Humbert, H. IBM J. Res. Dev. 1986, 30, 472.

(28) Alonso, C.; Salvarezza, R. C.; Vara, J. M.; Arvia, A. J.; Vázquez, L.; Bartolomé, A.; Baró, A. M. J. Electrochem. Soc. 1990, 137, 2161.

(29) Lin-Cai, J.; Pletcher, D. J. Electroanal. Chem. 1983, 149, 237.

(30) Standard Potentials in Aqueous Solutions; Bard, A. J., Parsons, R., Jordan, J., Eds.; Marcel Dekker: New York, 1985.

(31) Lau, A. L. Y.; Hubbard, A. T. J. Electroanal. Chem. 1970, 24, 237.

(32) Martell, A. E.; Smith, R. M. Critical Stability Constants; Plenum Press: New York, 1982.

(33) Adams, G. E.; Boszkiewicz, R. B.; Michael, B. D. Trans. Faraday Soc. $1968,64,1256$

(34) Gileadi, E.; Conway, B. In Modern Aspects of Electrochemistry; Bockris, J. O'M., Conway, B., Eds.; Butterworths: London, 1964; Vol. 3, Chapter 5 . 